\title{
Effect of Grinding Behavior on Liberation of Coal Macerals
}

\author{
Debjani NAG, ${ }^{*}$ Bidyut DAS, Rashmi SINGH, Santosh SRIRAMOJU, Ajinkya MESHRAM and \\ Pratik Swarup DASH
}

R\&D, Tata Steel, Jamshedpur, Pin-831001 India.

(Received on June 23, 2021; accepted on August 30, 2021)

\begin{abstract}
Macerals are the smallest organic constituents of coal. Reactive macerals or vitrinite is mainly responsible for coking potential of a coal during carbonization method. The effect of a novel grinding on coal maceral separation is studied in this work. The alternate method is based on grinding of coals by shearing compared to impact crushing as in other conventional methods like hammer mill. It is found that liberation of vitrinite is better in shearing. Coking properties of such maceral enriched coals showed improvement in laboratory coke making tests.
\end{abstract}

KEY WORDS: coal; maceral; shear crushing.

\section{Introduction}

Coal is an important raw material for blast furnace iron making. It is used to make coke which is part of the burden. Coal is basically a heterogeneous polymer with big aromatic ring and bridged with aliphatic chains. It is a sedimentary rock of organic composition consisting of carbon, hydrogen, oxygen and minor proportions of nitrogen and sulphur. The smallest organic building blocks of coal are known as maceral. The physical and chemical properties of the coal macerals ${ }^{1)}$ vary widely due to the variety of original plant materials and the extent of metamorphism. Based on their physical and chemical properties, macerals fall into three main groups, viz., vitrinite, liptinite and inertinite, in which vitrinite and liptinite are known as reactive macerals and inertinite as inert. The macerals are having difference in chemical and physical properties. ${ }^{2)}$ During crushing/grinding of coal, these macerals behave differently to different physical forces due to their difference in microhardness and elastic properties. ${ }^{3)}$ Many researchers attempted to determine material parameters of individual macerals and to study maturity-related changes, nano-indentation tests were carried out for this regard., ${ }^{3,4)}$ Measurements of microhardness of coal macerals would fully define the comminution behaviour of coal during pulverization. This difference in hardness can be attributed to varying coal rank. Some authors conducted experiment in order to find the effect of grindability index of coals on combustion behaviours. ${ }^{5)}$ Different studies have been conducted to find out the effect of grinding and crushing on devolatilization study of coal particles. ${ }^{6}$

\footnotetext{
*Corresponding author: E-mail: debjani.nag@tatasteel.com
}

Vitrinite maceral is the most desired component in coking coal, and these macerals is one of the substances in coal that produces its fluid characteristics and also contribute to plasticity of coal. ${ }^{7)}$ There are different methods reported in the literature for maceral/vitrinite enrichment. They are mostly based on hydrophobicity difference. ${ }^{8)}$

Gui et al. (2017), performed the experiment to study the liberation properties of middling coking coal. ${ }^{9)}$ Oliver et al., revealed that crushing increase both the liberation of mineral matter and clean coal. ${ }^{10)}$ Some studies conducted by the CSIRO, Australia, indicates that with the correct choice of comminution equipment, energy input, and feed and discharge arrangement it is possible to achieve the desired degree of selective breakage of coal particles. ${ }^{11)}$

Alan and Hower $(2003)^{12)}$ studied further the effect of micro lithotypes on grindability of coal. They have studied the grinding behaviour of coal based on pulverization. Both coal rank and maceral composition have an influence on grinding properties.

Recently, some researchers also studied the non-mechanical liberation of coal. ${ }^{13-16)}$ They use methods like electrical disintegration, high-voltage pulses or microwave pretreatment. The results of these studies indicated that the liberation of coal and ore by non-mechanical means generated a higher percentage of valuable components and lower percentage of fine material than mechanical liberation.

Few studies are available where separation of macerals has been done for efficient utilization in coke making. As mentioned, coal macerals can be separated in two groups: reactive and inert. During carbonization, these reactive macerals undergo through a plastic phase, which in turn imparts strength in resultant coke. The enriched macerals can be used as clean fuel for energy production and a range 
of other high value products. ${ }^{17)}$

There are very few studies conducted on the liberation of reactive macerals by different grinding and crushing techniques. It reveals that use of vitrinite rich coal in coke making leads to better coke properties. The enrichment of vitrinite in coal apart from conventional density separation techniques need innovative solution. Present investigation suggests a methodology for enrichment of reactive macerals by specific grinding and screening method. In this study, effort has been made to enrich vitrinite in different type of coal by a specific grinding technique. Also, experiments have been conducted to utilize these enriched coals in coke making. The application of this method is manifold. This would help in improving the coal blend properties and thus the coke properties. This would also help to enrich the coal with vitrinite and increase the value of poor coal in terms of coking.

\section{Coke Making Process}

The coal upgradation and coke making processes can be divided as follows: - Coal beneficiation, Coal blending, Coal crushing and Carbonization.

In Tata Steel, coke plant received washed coal of size $-13 \mathrm{~mm}$ from washeries. Typically, these coals are mixed in different proportion and crushed in the hammer mill. The size of the coal blend is maintained below $3 \mathrm{~mm}$. After crushing the coal blend is charged in the coke oven for carbonization. Carbonization is basically heating of coal in absence of air. In this method the reactive macerals/vitrinte passes through a plastic, visco-elastic phase.The plastic stage is the most important transformation in terms of coke making. The plastic mass covers the non-reactive macerals and upon further heating during the re-solidification of mass forms the matrix macerals. Whereas the inertinite does not participate much in the reaction and impart strength to the matrix. Hence, volume and nature of vitrinite is very important to get desire coke properties. Coke making process is a complex process of devolatilization of coal where not only chemical but the physical structure of coal changes to form a hard-porous mass called coke.

In the present study, an innovative approach in coal crushing has been introduced. Generally, in coke making coal crushed by hammer mill before carbonization. In present study, we used an alternative approach to crush the coal by shear stress. This methodology improves the vitrinite liberation in the coal. Which in turn improve the coking properties of coal.

\section{Experimental}

Selection of coal: For this study three types of coal having different properties have been selected. They are designated as $\mathrm{A}, \mathrm{B}$ and $\mathrm{C}$. The coals are characterized in terms of ash, volatile matter (VM), crucible swelling number (CSN) and petrography. The proximate analysis of these coals is presented in Table 1.

Comminution: Two type of comminution devices used in this study. Around 10-20 kg sample drawn from 100 $\mathrm{kg}$ as received coal by coning-quartering method. Then it is passed through $5 \mathrm{~mm}$ screen. After screening, it is sub-
Table 1. Properties of coal.

\begin{tabular}{ccc}
\hline Coal & Ash, \% db & VM, \% db \\
\hline A & 14.5 & 28.5 \\
B & 17.3 & 21.0 \\
C & 8.8 & 19.4 \\
\hline
\end{tabular}

jected to crush by two different techniques. It is then sent for further characterization as mentioned above. Grinding of the samples has been conducted in following two devices. One was hammer mill where breakage is predominantly by impact of the hammers on the coal. The hammer mill used in this experiment is a laboratory hammer mill.

A mill has been designed which is a horizontal plate crusher type. In which particle breakage take place by shear. This mill has been designed and developed in a small laboratory scale $(1 \mathrm{~kg} / \mathrm{hr})$. The design is patented by Tata Steel.

Petrography: The coal samples from both the crushing method are subjected to petrographic analysis. Petrographic analysis determines the volume percent of different macerals and rank of the coal. The microscopic studies are done by Leica DM6000 microscope along with QWIN software.

FTIR analysis: Samples for the FTIR studies were prepared by the $\mathrm{KBr}$ pellet technique and the Nicolet 6700 FTIR spectrometer was used to record the spectra with 256 scans from $4000-400 \mathrm{~cm}^{-1}$. Spectra were obtained using the standard software package on OMNIC 7a package.

Carbonization test: Several carbonization tests are conducted in the 7-kg Carbolite test oven, under stamp charging conditions using a standard procedure established at R\&D, Tata Steel. The coal samples to be used for making the coal blends are crushed to a fineness of $90 \%$ below $3.2 \mathrm{~mm}$. Water was added to the coal blend to obtain the desired value of moisture content. The coal cake was made inside a cardboard box keeping the bulk density $1150 \mathrm{~kg} / \mathrm{m}^{3}$. The final coal cake thus made is charged into the test oven. Before charging the coal cake into the oven, it is ensured that the empty oven temperature is $900 \pm 5^{\circ} \mathrm{C}$. After carbonization, the coke sample were tested for their coke strength after reaction (CSR).

Stability determination of coal cake: Two different equipment is used to determine the coal cake stability. One for making the coal cake and another for determining the shear and compressive strength. ${ }^{18)}$ The coal cake was produced in a die into which the charge is fed and compacted with a rammer to a cylindrical shape of $50 * 50 \mathrm{~mm}$. The test cake was made after determining the number of drops required to produce cake with specified stamping energy. The coal cake was then subjected to testing in the second equipment for the determination of compressive and shear strength. The minimum shear and compressive strength require for stable coal cake are around $14709 \mathrm{~N} / \mathrm{m}^{2}$ and $156906 \mathrm{~N} /$ $\mathrm{m}^{2}$ respectively. ${ }^{19)}$

\section{Results \& Discussion}

\subsection{Size Distribution}

Coal A is subjected to crushing in hammer mill and by shear crushing as well. Figure 1 represents the size analysis of the coal. It is found that shear crushing makes the size 
distribution narrower. It again supports the hypothesis that more controlled crushing is possible with shear crushing technique. Same trend has been followed by two other coals $\mathrm{B}$ and $\mathrm{C}$.

Petrographic analysis is the most important analysis to establish the liberation of vitrinite. Figure 2 shows the vitrinite concentration of the three coal samples (A, B and C) for conventional hammer mill crushing and alternate crushing by shearing.

It shows that, the amount of vitrinite has increased in each case for alternative crushing. So, higher vitrinite concentration is observed in case of alternative crushing indicates vitrinite got liberated due to shear crushing. Figure 3 shows the micrograph of petrography of normal crushing and alternative crushing of same coal. It was found that, in shear crushing (c and d) preferential breakage takes place for the vitrinite particles. This may cause the higher percentage of vitrinite under microscope. ${ }^{17)}$

FTIR analysis is performed for coals grinded with dif-

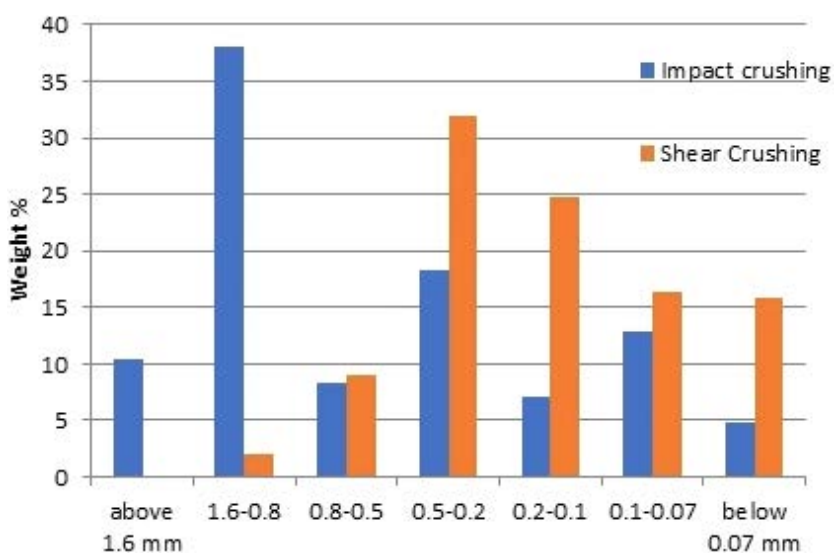

Fig. 1. Size distribution of coal A in two different types of grinding. (Online version in color.)

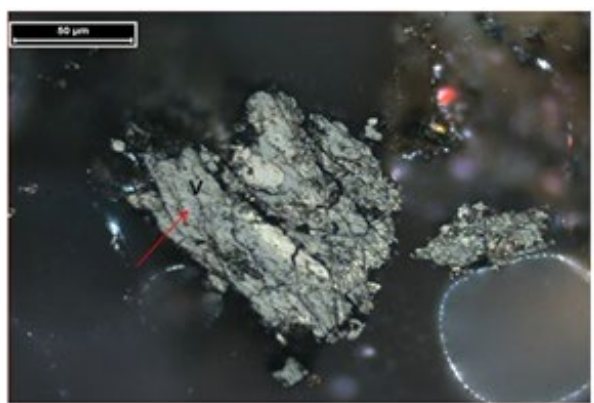

a

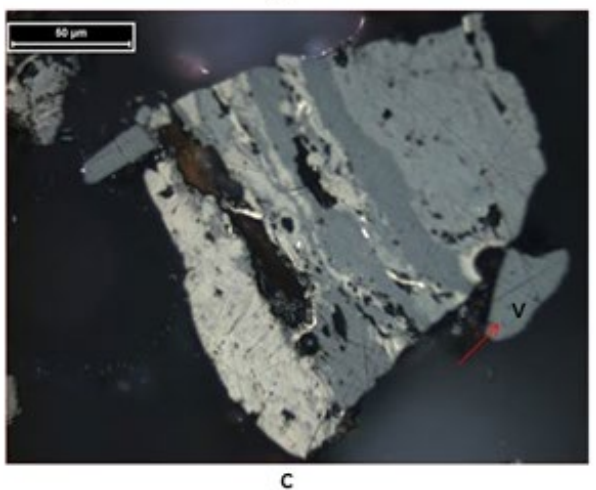

Fig. 3. Micrograph of coal: V-vitrinite, I-inertinite. (Online version in color.) ferent mechanisms i.e. impact crushing and shear crushing to understand its mechanism in altering different molecular vibrations. It is observed that (Fig. 4), the intensity of transmittance for Si-O vibrations $\left(950-1150 \mathrm{~cm}^{-1}\right.$ wave number) is constant, as there is no change in the mineral phases present in the coal. However, change in the intensity for aromatic hydrogen bonds $\left(820 \mathrm{~cm}^{-1}\right.$ wave number $)$ is observed. The intensity was higher for shear grinded coal compared to coal grinded with impact forces. This aromatic hydrogen plays a major role in improving the coke properties, as the early release of hydrogen improves the coking behaviour of coal. The molecular vibrations with respect to C-O stretching and $\mathrm{OH}$ deformation of $\mathrm{COOH}$ (1 280-1 200 $\mathrm{cm}^{-1}$ wave number) are not changed significantly, which gives a clear indication that, the oxidation levels are not changed. IR bands belongs to $\mathrm{C}=\mathrm{C}\left(1517-1590 \mathrm{~cm}^{-1}\right.$ wave number), $\mathrm{C}=\mathrm{O}\left(1725-1720 \mathrm{~cm}^{-1}\right.$ wave number), Quinoline (1 820-1 $805 \mathrm{~cm}^{-1}$ wave number), and different $\mathrm{OH}$ vibrations (3 400-3 $700 \mathrm{~cm}^{-1}$ wave number) are same

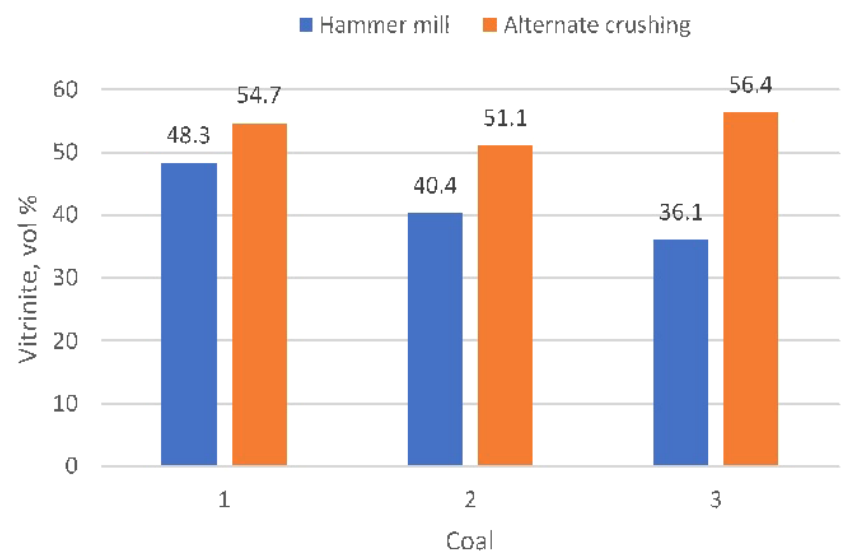

Fig. 2. Vitrinite concentration of coals for different crushing. (Online version in color.)

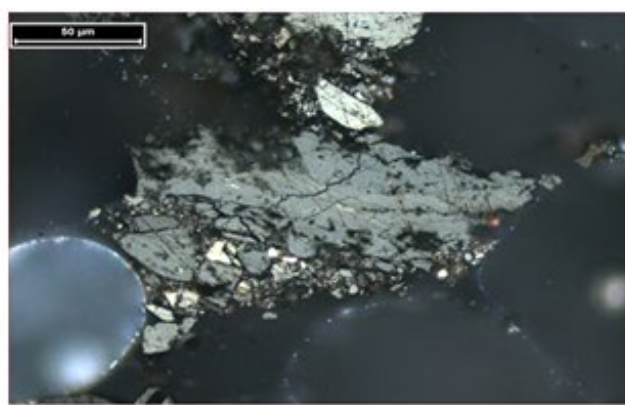

b

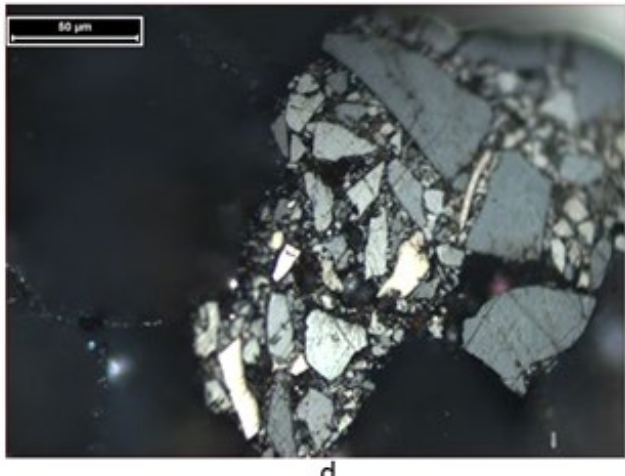


for both the compounds. However, changes are found in aliphatic region (300-2 $700 \mathrm{~cm}^{-1}$ wave number). In order to study the changes in aliphatic region in more detail, deconvolution technique is used and the results are depicted in Fig. 5 and Table 2. It was observed that, the intensity of peaks for symmetric $\mathrm{CH}_{2}$, asymmetric $\mathrm{CH}_{2}$, symmetric $\mathrm{CH}_{3}$, asymmetric $\mathrm{CH}_{3}$ shows different intensity and the ratio of aliphatic $\mathrm{CH}_{2}$ and $\mathrm{CH}_{3}$ was lower for impact crushing compared to shear crushing. However, the area under the curve for aliphatic and aromatic groups is constant $\left(\mathrm{A}_{\mathrm{t}}\right.$ - total area).

Higher vitrinite leads to improvement in caking properties of coals. Crucible Swelling Number (CSN) and Geissler fluidity is a measure of it. Higher value indicates better caking property. Table 3 shows different coking potential for

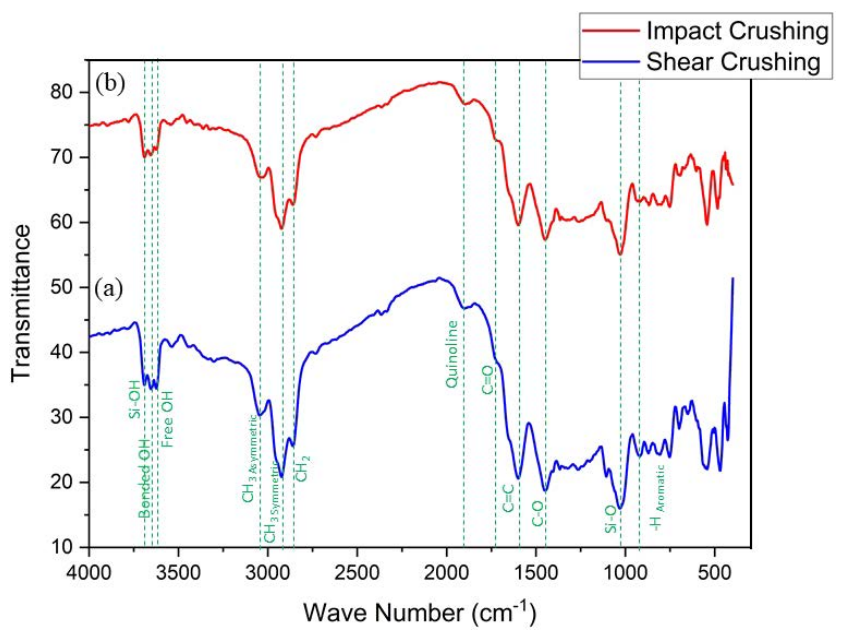

Fig. 4. FTIR analysis of (a) shear crushed coal and (b) coal by impact crushing. (Online version in color.)

(a)

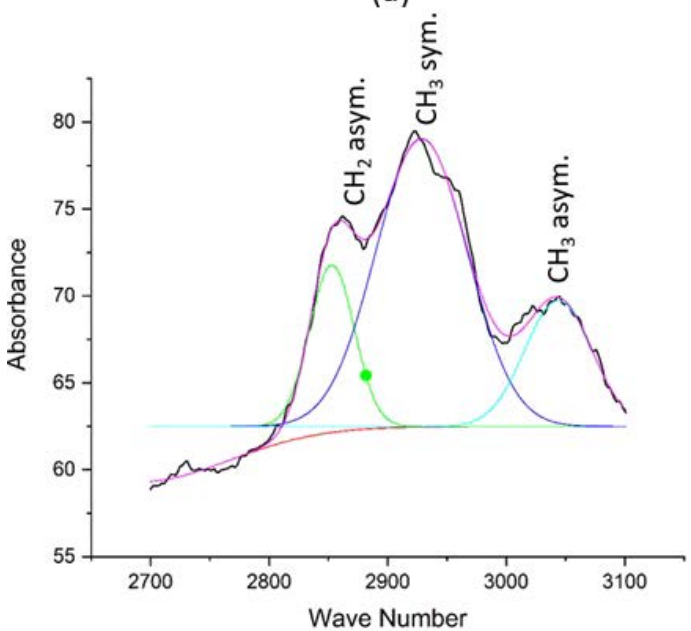

conventional crushing (CC) and alternative crushing (AC) by shearing. This indicates liberated vitrinite improved caking property of coal as well.

Based on these findings, carbonization study was conducted by designing suitable blends with these three individual coals crushed by conventional crushing and alternate crushing. Series of blends are also designed applying both types of crushing and tested in carbonization oven.

Initially, three coals A, B and C are tested individually in laboratory scale carbonization oven with $100 \%$ of the coal crushed in hammer mill. Then $10 \%$ of the coal is crushed by alternative crushing applying shearing method in each case and mixed with $90 \%$ of conventionally crushed coal. Then again carbonization tests are conducted. All the product cokes are subjected to CSR/CRI test. Table 4 describes the philosophy of carbonization tests and coke properties. In all the cases, it shows that when $10 \%$ of the coal is crushed by alternate crushing (AC) and mixed with conventionally crushed (CC) coal, the CSR of the product coke improved. As the vitrinite percentage is higher in alternative crushed coal, the coking potential of the blend improved, which reflects in higher CSR.

$\mathrm{Lab}$ scale result indicate improvement in all the cases. The reason behind the increase in coal properties is attributed to liberation of individual macerals particularly, reactive macerals. This provided efficient bonding between reactive and non-reactive macerals to result in better coal properties.

The alternatively crushed coal proportion is restricted to $10 \%$ only. If more than $10 \%$ of the alternatively crushed coal added to blend there is certain issue of coal cake stability. The shear strength of the coal cake decreases with more percentage of shear crushed coal as the granulometry of

Fig. 5. Deconvolution of aliphatic zone of (a) shear crushed coal and (b) coal by impact crushing. (Online version in color.)

Table 2. Quantitative analysis of coal crushed by different crushing methodologies.

\begin{tabular}{|c|c|c|c|c|c|c|c|c|}
\hline \multirow{2}{*}{ Type of grinding } & \multicolumn{8}{|c|}{ Fraction of components } \\
\hline & $\mathrm{A}_{\text {aliphatic }} / \mathrm{A}_{\mathrm{T}}$ & $\mathrm{A}_{\text {aromatic }} / \mathrm{A}_{\mathrm{T}}$ & $\mathrm{A}_{\text {Aliphatic }} / \mathrm{A}_{\text {Aromatic }}$ & $\mathrm{A}_{\text {silica }} / \mathrm{A}_{\mathrm{T}}$ & $\mathrm{A}_{\mathrm{OH}} / \mathrm{A}_{\mathrm{T}}$ & $\mathrm{A}_{\mathrm{CH} 3} / \mathrm{A}_{\mathrm{T}}$ & $\mathrm{A}_{\mathrm{CH} 2} / \mathrm{A}_{\mathrm{T}}$ & $\mathrm{A}_{\mathrm{CH} 2} / \mathrm{A}_{\mathrm{CH} 3}$ \\
\hline Shear crushing & 0.119 & 0.063 & 1.861 & 0.623 & 0.534 & 0.092 & 0.046 & 0.50 \\
\hline Impact crushing & 0.117 & 0.061 & 1.902 & 0.684 & 0.533 & 0.069 & 0.032 & 0.46 \\
\hline
\end{tabular}


Table 3. Coking potential of coal samples in different crushing.

\begin{tabular}{ccccccc}
\hline Coal & \multirow{2}{*}{ CSN } & \multicolumn{2}{c}{$\begin{array}{c}\text { Max Fluidity, ddpm } \\
\text { (dial divisions per minute) }\end{array}$} & \multicolumn{2}{c}{ Fluid range, $\mathrm{K}$} \\
\hline & CC & AC & CC & AC & CC & AC \\
\hline A & 6 & 7.5 & 278 & 658 & 331 & 338 \\
B & 5 & 6 & 2066 & 2688 & 333 & 342 \\
C & 1 & 2 & Nil & Nil & - & - \\
\hline
\end{tabular}

Table 4. Carbonization study.

\begin{tabular}{ccrc}
\hline Experiment & Blend & $\%$ & CSR, \% \\
\hline 1 & Coal A (C C) & 100 & 54 \\
\hline \multirow{2}{*}{2} & Coal A (C C) & 90 & 58 \\
& Coal A (A C) & 10 & \\
\hline 3 & Coal B (C C) & 100 & 49 \\
\hline \multirow{2}{*}{4} & Coal B (C C) & 90 & \multirow{2}{*}{52} \\
& Coal B (A C) & 10 & \\
\hline 5 & Coal C (C C) & 100 & 32 \\
\hline \multirow{2}{*}{6} & Coal C (C C) & 90 & \multirow{2}{*}{37} \\
& Coal C (A C) & 10 & \\
\hline
\end{tabular}

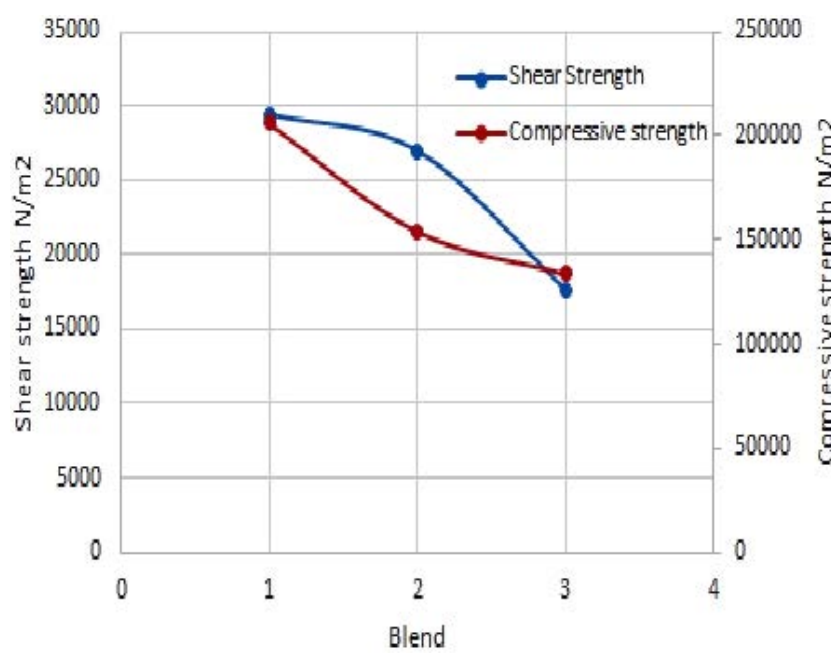

Fig. 6. Coal cake stability for different crushing. (Online version in color.)

this coal is different. Figure $\mathbf{6}$ shows the shear strength and compressive strength of the coal cake of different blends. Blend 1, 2 and 3 are 10\%, 15\% and 20\% shear crushed coal in blend. base blend and blend with $10 \%$ crushed coal. In most of the cases strength decreases with increase in shear crushed coal.

\section{Conclusions}

In case of coal crushing/grinding mostly the objective of size reduction is separation of mineral. Very little emphasis given on the liberation of maceral by different types of crushing and grinding. Here, a methodology of alternative crushing proposed in order to enhance the liberation of macerals in coal. The key finding from these studies are: (i) With the application of shear crushing the liberation of vitrinite macerals increased (ii) The size distribution of alternatively crushed particle is narrower than the conventionally crushed particle. (iii) There is improvement of fluidity and crucible swelling number for the alternatively crushed coal (iv) When $10 \%$ of the coal is crushed alternatively and mixed with $90 \%$ of conventionally crushed coal, the mixed blend shows improvement in CSR compare to $100 \%$ conventionally crushed coal.

This study opens an avenue to look the crushing for liberation of reactive maceral in coal. It reveals that alternate crushing based on shearing, improves the coking potential of different coal. This suggests a complete study with number of different categories of coal.

\section{Acknowledgement}

Authors are thankful to Prof. A. K. Lahiri and Dr. S. Chandra for their useful suggestions during this work. Thanks to Tata Steel Management for allowing this study.

\section{REFERENCES}

1) A. C. Scott: Int. J. Coal Geol., 50 (2002), 119.

2) R. Q. Honaker, M. K. Mohanty and J. C. Crelling: Miner. Eng., 9 (1996), 449.

3) S. Vranjes, D. Misch, T. Schöberl, D. Kiener, D. Gross and R. F. Sachsenhofer: Adv. Geosci., 45 (2018), 73.

4) R. F. Sachsenhofer, V. A. Privalov, A. Izart, M. Elie, J. Kortensky, E. A. Panova, A. Sotirov and M. V. Zhykalyak: Int. J. Coal Geol., 55 (2003), 225.

5) J. C. Hower: Int. J. Coal Geol., 73 (2008), 213.

6) C. K. Man, J. Jacobs and J. R. Gibbins: Fuel Process. Technol., 56 (1998), 215.

7) D. Nag, P. Kopparthi, P. S. Dash, V. K. Saxena and S. Chandra: Metall. Res. Technol., 115 (2018), 209.

8) B. J. Arnold and F. F. Aplan: Fuel, 68 (1989), 651.

9) X. Gui, Z. Yang, Y. Xing, D. Wang and J. Ran: Powder Technol., 319 (2017), 483.

10) E. T. Oliver, J. Abbott and N. J. Miles: Coal Prep., 16 (1995), 167.

11) N. Lockhart: Aust. Coal J., 37 (1992), 11.

12) A. S. Trimble and J. C. Hower: Int. J. Coal Geol., 54 (2003), 253.

13) U. Andres, I. Timoshkin, J. Jirestig and H. Stallknecht: Powder Technol., 114 (2001), 40.

14) U. Andres and R. Bialecki: Powder Technol., 48 (1986), 269.

$15)$ D. N. Whittles, S. W. Kingman and J. D. Reddish: Int. J. Miner. Process., 68 (2003), 71.

16) V. Singh, I. Obed Samuelraj, R. Venugopal, G. Jagadeesh and P. K. Banerjee: Miner. Eng., 70 (2015), 207.

17) D. Nag, S. K. Sriramoju and A. K. Lahiri: Mater. Today: Proc., 5 (2018), 17041.

18) S. H. Krishnan, P. S. Dash, M. Guha, D. Kumar and D. P. Deshpande: ISIJ Int., 44 (2004), 1150.

19) P. S. Dash, S. H. Krishnan, R. Sharma, P. K. Banerjee and S. K. Haldar: ISIJ Int., 45 (2005), 1577. 